\title{
EXPERIMENTATION ON EMISSION ANALYSIS OF A COMPRESSION IGNITION ENGINE RUN WITH BIODIESEL
}

\author{
R. Sundara Raman ${ }^{1, *}$, G. Sankara Narayanan², N. Manoharan ${ }^{3}$ \\ and S. Sendilvelan ${ }^{4}$ \\ ${ }^{1}$ Department of Mechanical Engineering, AMET University, 135, \\ East Coast Road, Chennai-603 112 \\ ${ }^{2}$ Recognized Research Supervisor - AMET University, 135, East Coast Road, \\ Chennai-603 112 / Dean PG Studies \& Research, Sree Sastha Institute of \\ Engineering and Technology, Chembarambakkam, Chennai \\ ${ }^{3}$ Director, Research, AMET University, Chennai \\ ${ }^{4}$ Department of Mechanical Engineering, Dr. MGR Educational and Research \\ Institute University, Maduravoyal, Chennai \\ *E-mail: sundararaman792@gmail.com
}

\begin{abstract}
In this research esterified Rice Bran Oil (RBO) and non-esterified RBO was investigated for its performance as a diesel engine fuel. In this context experiments were conducted on a single cylinder water cooled diesel engine with diesel, RBO, preheated RBO and biodiesel (esterified RBO). Performance parameters like thermal efficiency, specific fuel consumption, and emissions such as smoke, particulate matter, unburned hydrocarbon, carbon monoxide and oxides of nitrogen have been measured. The performance of the engine with diesel has been used as the basis for comparison. In the existing work, it is detected that the $\mathrm{NO}_{\mathrm{X}}$ and unburned hydrocarbon emission reductions and carbon monoxide, particulate emission and smoke intensity upsurges utilizing biodiesel in a diesel engine.
\end{abstract}

Keywords: RBO, Esterified RBO, Emissions, Diesel Engine.

(C) RASĀYAN. All rights reserved

\section{INTRODUCTION}

The rapid depletion of non-renewable petroleum fuel and the environmental pollution caused by the burning of petroleum fuels have directed to an intensive search for alternative fuels ${ }^{1}$.

Out of the three specific alternative fuels solid, gaseous and liquid fuels, considerable work was done on gaseous and liquid fuels ${ }^{1}$. Liquid fuels such as Bio-diesel, vegetable oils, and alcohols and gaseous fuels like Compressed Natural Gas (CNG), Liquefied Petroleum Gas (LPG), methane and hydrogen were found to be promising for the use in C.I. and S.I. Engines. ${ }^{2}$

John W. Goodrum et $a l^{1}$ experimentally determined peanut oil-diesel fuel blends fundamental physical properties to support aptness for use in compression-ignition engines. For volumetric proportions of peanut oil ranging in $20 \%$ increments from $0 \%$ to $100 \%$, the continuously varying properties at $21^{\circ} \mathrm{C}$ were found to range as follows: heating value 45.8 to $30.3 \mathrm{MJ} / \mathrm{Kg}$; specific gravity 0.848 to 0.915 ; surface tension 28.3 to $35.6 \mathrm{mN} / \mathrm{m}$ and kinematic viscosity 3.8 to $7.0 \mathrm{CS}$.

C.E. Goering et $a l^{2}$ have studied chemical and fuel properties of some vegetable oils. Oil samples were subjected to ASTM tests suitable for diesel fuels. The tests recognized some problem areas that are found with vegetable oil fuels. The oil samples were also categorized chemically and thus certain fuel properties were correlated to chemical compositions.

A comprehensive review was attempted by Bhattacharya et $a l^{3}$ on the use of vegetable oil as fuel for 
stationary C.I. engines. Specific vegetable oils were reviewed individually and a relative survey was presented. Normally short term engine tests have been positive with vegetable oil; long-term tests have revealed the fuel's limitations according to lubricant contamination, deposits on engine surfaces and injection issues which unfavorably affected engine durability and its performance in the long term. Transesterification of some oils was reported to gain better long-standing performance. Different blends with diesel oil and pure vegetable oil have been deployed as engine fuels for relative performance studies and the best mixes sought for dissimilar oils.

Prasad et $a l^{4}$ have evaluated the non-edible vegetable oils such as Pongamin Oil and Jatropha Oil which were found to be effective substitute fuels in the low heat rejection diesel engine. Esterification, preheating and increase in injection pressures have been tried for effective utilization of the vegetable oils. Performance factors like the exhaust gas temperature and the brake specific energy consumption have been reported for changing magnitudes of brake mean effective pressure with different non-edible vegetable oils as substitute fuels. The pollution levels of black smoke and $\mathrm{NO}_{\mathrm{x}}$ have been recorded.

Seppo A. Nilemi et $a l^{5}$ have investigated the performance and exhaust emission of a DI tractor diesel engine using mustard seed oil as fuel. Two dissimilar mustard seed oils (MSOs) were tested. The unesterized MSOs were cleaned by letting them stand and clear. There were no alterations made to the turbocharged diesel engine. The engine made brake torque with MSOs was moreover the same to the diesel fuel oil (DFO). Relatively comparable brake thermal efficiencies were measured with MSOs than being measured with DFO. Usage of MSOs decreased the exhaust smoke and $\mathrm{NO}_{\mathrm{x}}$ emissions. There were no big differences among the fuels recognized when the exhaust $\mathrm{HC}$ emissions were determined.

Diesel fuel and oleic safflower oil of high 25-75 (v/v) blend, a non-ionic sunflower oil-aqueous ethanol microemulsion, a 25-75 blend (v/v) of refined-alkali sunflower oil as well as diesel fuel and a methyl ester of sunflower oil were evaluated by Kenton R. Kaufman et $\mathrm{al}^{6}$ as fuels in a D.I. Turbocharged intercooled, 4-cylinder Allischalmers diesel engine during a 200 hour EMA cycle laboratory screening endurance test. Phillips 2-D mentioned fuels engine performance functioned as the standard line for these experimental fuels.

\section{Biodiesel}

Clean-burning diesel fuel is otherwise called as biodiesel which was made from both natural and renewable sources like vegetable oil ${ }^{3}$. It is also called as "mono alkyl esters".

\section{Properties of Biodiesel}

Bio diesel is the only substitute fuel that can be utilized directly in any current, unchanged diesel engine. ${ }^{4}$ Since it has comparative properties to petroleum diesel fuel, bio diesel can be combined in any percentage with petroleum diesel fuel. Pure biodiesel is nontoxic, biodegradable and really free from aromatics and sulphur. ${ }^{5}$ The engines tear and wear emissions have also been identified reducing the usage of Bio-diesel.

\section{Biodiesel Production}

Biodiesel is made by transesterification process. In this process triglyceride of vegetable oil is converted into glycerol and esters of fatty acid. ${ }^{6}$ This fatty acid ester is known as "Biodiesel". Glycerol is a by product of esterification process. The concentration ratio of alcohol to fuel, temperature, catalyst type and stirring rate impacts the esterification procedure to more noteworthy degree. ${ }^{7}$

\section{RBO}

Rice contains only a lesser quantity of oil. When paddy is milled, the germ and bran layers are separated from the endosperm. ${ }^{8}$ This forms the milling residue which is commonly known as "Rice Bran". The oil mined from Rice Bran is named as the 'RBO'. The oil content of bran is specified in the Table-1.

RBO contains a high proportion of mono-unsaturated fatty acids (40-50\%) and di-unsaturated fatty acids $(29-42 \%)$. The Table- 2 shows the cost of various fuels. The chemical composition of RBO is given in the Table-3. 


\section{Problems in direct use of RBO}

The foremost problem with the direct usage of RBO as fuel in Diesel Engines is their greater viscosity. It interferes fuel injection and atomization and contributes to incomplete combustion, nozzle clogging, excessive engine deposits, ring sticking, the impurity of lubricating oil, etc., The problem of the greater viscosity of vegetable oils can be overwhelmed to a larger extent by various techniques, such as preheating, dilution, emulsification, and esterification, etc.

Table-1: Oil content of bran from different mills

\begin{tabular}{c|c|c}
\hline Mill Type & Grade & Oil Content (\%) \\
\hline Huller & Raw & $4-6$ \\
\hline & Parboiled & $4-6$ \\
\hline Shelter & Raw & $12-15$ \\
\hline & Parboiled & $15-20$ \\
\hline Modern & Raw & $15-20$ \\
\hline & Parboiled & $25-30$ \\
\hline
\end{tabular}

\section{Ester of RBO}

A single mole of the RBO and another three moles of ethanol are taken in a round bottom flask. The mixture is stirred vigorously and heated to about $70^{\circ} \mathrm{C}$ for one hour since $\mathrm{RBO}$ and ethanol are immiscible liquids. Now, the mixture is cooled to $50^{\circ} \mathrm{C}$, and then sodium hydroxide and little amounts of ethanol are added. Here sodium hydroxide acts as a catalyst. Again the mixture is heated to about $70^{\circ} \mathrm{C}$ for one hour and stirred vigorously. The reaction takes place and three moles of fatty acids and one mole of glycerol are produced. Glycerol is valuable by product. ${ }^{9}$

Now the solution is cooled to $50^{\circ} \mathrm{C}$ and some amount of concentrated hydrochloric acid and cool water are added. Then it is permitted to cool full night at room temperature without stirring. Two layers are formed. The bottom layer consists of glycerol and the top layer is the ester otherwise called biodiesel. It is separated from the glycerol and then used as fuel. ${ }^{10}$

Table-2: Cost of various fuels

\begin{tabular}{c|c|c}
\hline S. No. & Fuels & Cost per liter in Rs. \\
\hline 1. & Gasoline & 66 \\
\hline 2. & Diesel & 50 \\
\hline 3. & RBO & 44 \\
\hline 4. & Biodiesel & 43 \\
\hline
\end{tabular}

Table-3: Chemical composition of RBO

\begin{tabular}{c|c|c}
\hline S. No. & Fuels & RBO \\
\hline 1. & Myristic & $0.4-1.0$ \\
\hline 2. & Palmitic & $12-18$ \\
\hline 3. & Stearic & $1-3$ \\
\hline 4. & Oleic & $40-50$ \\
\hline 5. & Linoleic & $29-42$ \\
\hline 6. & Linolenic & $0.5-1.0$ \\
\hline 7. & Arachidic & 0 \\
\hline 8. & Beberic \& Lignoceric & 0.2 \\
\hline
\end{tabular}

\section{Chemical reaction in Biodiesel production}

$\mathrm{RBO}$, when reacted with ethanol in the presence of $\mathrm{NaOH}$, gives glycerol and ethyl ester of $\mathrm{RBO}$.

\section{Properties of RBO Ester}

The viscosity of RBO Ester is very low compared to Raw RBO. The density of the Raw RBO Ester is also reduced and comparable one with a diesel. The calorific value of the ester is slightly reduced. But the 
cetane number of the ester is increased from the raw RBO. Cetane number, flash point and carbon residue of the ester is decreased from the raw oil values. ${ }^{11}$ The properties of RBO and its ester are given in the Table-4.

\begin{tabular}{c|c|c|c|c}
\multicolumn{5}{c}{ Table-4: Properties of RBO and its Ester } \\
\hline S. No. & Properties & Diesel & $\begin{array}{c}\text { Rice } \\
\text { Bran Oil }\end{array}$ & $\begin{array}{c}\text { Rice Bran } \\
\text { Oil Ester }\end{array}$ \\
\hline 1. & Density & 840 & 910 & 875 \\
\hline 2. & $\begin{array}{c}\text { Calorific Value } \\
\mathrm{KJ} / \mathrm{Kg}\end{array}$ & 43000 & 39465 & 38190 \\
\hline 3. & Viscosity at $38^{\circ} \mathrm{C}$ & 2.7 & 38.5 & 3.9 \\
\hline 4. & Cetane Number & 47 & $40-45$ & 50 \\
\hline 5. & Flash Point ${ }^{\circ} \mathrm{C}$ & 52 & 240 & 180 \\
\hline 6. & Carbon Residue $\% \mathrm{~W}$ & 0.35 & 0.24 & 0.10 \\
\hline
\end{tabular}

\section{Experimental Programme for Emission Measurement}

This chapter describes the experimental techniques carried on how to work on the engine with various fuels such as Diesel, Raw and as well preheated RBO and Biodiesel (RBO Ester).

\section{Base Line Testing}

The flow of cooling water, the level of lubricant and the fuel level are checked while starting the engine. Diesel is used as fuel for this testing. ${ }^{12}$ The load on the engine is released and it is cranked by retaining the decompression lever and the fuel act off lever of the fuel pump in the ON position. When the engine begins, the decompression lever is disengaged and the speed of the engine is increased to $1500 \mathrm{rpm}$ and maintained. Thus, the engine is allowed to run for 15 minutes to reach the steady state conditions. The times taken for $10 \mathrm{CC}$ of fuel consumption and the hydrocarbon, $\mathrm{CO}$, smoke, particulate matter, NOx and exhaust temperature are measured. ${ }^{13}$ Then the load is changed in steps of $20 \%$ and after reaching the steady state condition all the above readings are taken. The test is repeated up to $100 \%$ load. Before stopping, all the loads are released and the engine is brought to zero loads.

\section{Testing with Raw RBO}

The flow of cooling water, the level of lubricant and the fuel level are checked while starting the engine. For this testing Raw RBO is used as fuel. The load on the engine is released and the engine is cranked by keeping the decompression lever and the fuel act off the level of the fuel pump in the ON position. When the engine starts, the decompression lever is disengaged and the speed of the engine is increased to 1500 rpm and maintained. ${ }^{14}$ Thus, the engine is allowed to run for 15 minutes to reach the steady state conditions. Then the time taken for $10 \mathrm{CC}$ of fuel consumption and the hydrocarbon, CO, smoke, particulate matter, NOx and exhaust temperature are measured. Then the load is changed in steps of 20\% and after reaching the steady state condition all the above readings are taken. The test is repeated up to $100 \%$ load. Before stopping, all the loads are released and the engine is brought to zero load. ${ }^{15}$

\section{Testing with preheated RBO}

$\mathrm{RBO}$ is found to be highly viscous oil and it will block the injector nozzle and may damage the fuel pump and the injector nozzle in long term operation. ${ }^{16}$

The heating process reduces the viscosity and decomposes the components in the composition of the RBO. The optimum temperature for this purpose is $100^{\circ} \mathrm{C}$ and thus maintaining the temperature of the fuel around $100^{\circ} \mathrm{C}$ is found suitable for the experiment.

\section{Heating and Testing Procedure}

Oil is filled in the fuel tank and the level of fuel in noted down. Heating is done electrically by an immersion heater. The immersion heater is suspended from the top into the fuel tank till its coils are fully immersed in the fuel. The thermometer is immersed in the burette till its bulb is inside the fuel column. 
The heater is switched on and the temperature rise was followed. For maintaining the temperature of the fuel around $100^{\circ} \mathrm{C}$, a temperature control unit can be used.

The flow of cooling water, the level of lubricant and the fuel level are checked while starting the engine. For this testing Preheated RBO is used as fuel. The load on the engine is released. The engine is cranked by keeping the decompression lever and the fuel act off lever of the fuel pump in the ON position. When the engine starts, the decompression lever is disengaged and the speed of the engine is increased to 1500 $\mathrm{rpm}$ and maintained. Thus, the engine is allowed to run for 15 minutes to reach the steady state conditions. The times taken for $10 \mathrm{CC}$ of fuel consumption and the hydrocarbon, $\mathrm{CO}$, smoke, particulate matter, NOx and exhaust temperature are measured. Then the load is changed in steps of $20 \%$ and after reaching the state of steady condition, all the above readings are noted. The test is repeated up to $100 \%$ load. Before stopping all the loads are released and the engine is brought to zero loads. The constant temperature of the fuel is maintained in this whole process. ${ }^{17}$

\section{Testing with Biodiesel}

The cooling water flow, lubricant level, and the fuel level are checked while starting the engine. For this testing, Biodiesel is used as fuel. The load on the engine is released. The engine is cranked by keeping the decompression lever and the fuel act off lever of the fuel pump in the ON position. When the engine starts, the decompression lever is disengaged and the speed of the engine is increased to $1500 \mathrm{rpm}$ and maintained. ${ }^{18}$ Thus, the engine is allowed to run for 15 minutes to reach the steady state conditions. The times taken for $10 \mathrm{CC}$ of fuel consumption and the hydrocarbon, $\mathrm{CO}$, smoke, particulate matter, NOx and exhaust temperature are measured. After that, the load is changed in steps of $20 \%$ and after getting the steady state condition all the above readings are taken. The test is repeated up to $100 \%$ load. Before stopping all the loads are released and the engine is brought to zero loads. ${ }^{19}$

\section{Experimental Uncertainty}

The engine exhaust emission like $\mathrm{CO}, \mathrm{HC}, \mathrm{NO}_{\mathrm{x}}$, smoke and particulate matter is calculated by using appropriate instruments.

\section{CO Measurement}

$\mathrm{CO}$ is measured by using Exhaust Gas Analyser. The analyzer is switched on and left for 5 minutes to warm up. From the main menu, the reading option is selected. Then the sample gas is admitted to the analyzer by using a probe. Finally, the readings are taken from the screen display. CO is measured in $\%$ volume unit.

\section{Exhaust Gas Analyser}

It is a fully microprocessor controlled exhaust gas analyzer employing Non-Dispersive Infra-Red (NDIR) Technique. The analyzer measures carbon monoxide, hydrocarbons, carbon dioxide and oxygen in the exhaust. Zero calibration can be ordered at any wanted time by the operator and automatically executed by the analyzer. An automatic auto zero check is performed every thirty minutes when the analyzer is switched on.

\section{HC Measurement}

The unburned hydrocarbon is measured by exhaust gas analyzer. It is measured in ppm volume unit.

\section{$\mathrm{NO}_{\mathrm{x}}$ Measurement}

$\mathrm{NO}_{\mathrm{x}}$ is measured by using Exhaust Gas Analyser. $\mathrm{NO}_{\mathrm{x}}$ is measured in ppm volume unit.

\section{Technovation-89 Gas Analyser}

The heart of the instrument is an electrochemical sensor which converts the concentration of gas encountered around it into an electrical signal which is sensed, amplified, compensated, and displayed by the instrument in terms of ppm on LCD. 


\section{Measurement of Smoke Intensity}

Smoke intensity is measured by IIP smoke meter. The filter paper is placed on the filter paper disc. The gas trial is drawn through the filter paper. Then the filter paper is evaluated by means of photocell reflector meter unit to give a precise assessment of the intensity of the spot. The intensity of the spot is measured on a scale of 10 arbitrary units called Bosch Smoke Unit (BSU).

\section{EXPERIMENTAL}

The experimental set-up is as shown in the Fig.-1. The engine used in this investigation is a four stroke, water cooled, single cylinder, direct injection and vertical diesel engine at $3.78 \mathrm{KW}$ running at $2000 \mathrm{rpm}$. The engine is mounted on the bed with suitable connections for lubrication and cooling water supply. The fuel is supplied from a fuel tank with three-way cock to allow the fuel either from the tank or through the burette. ${ }^{13,18}$

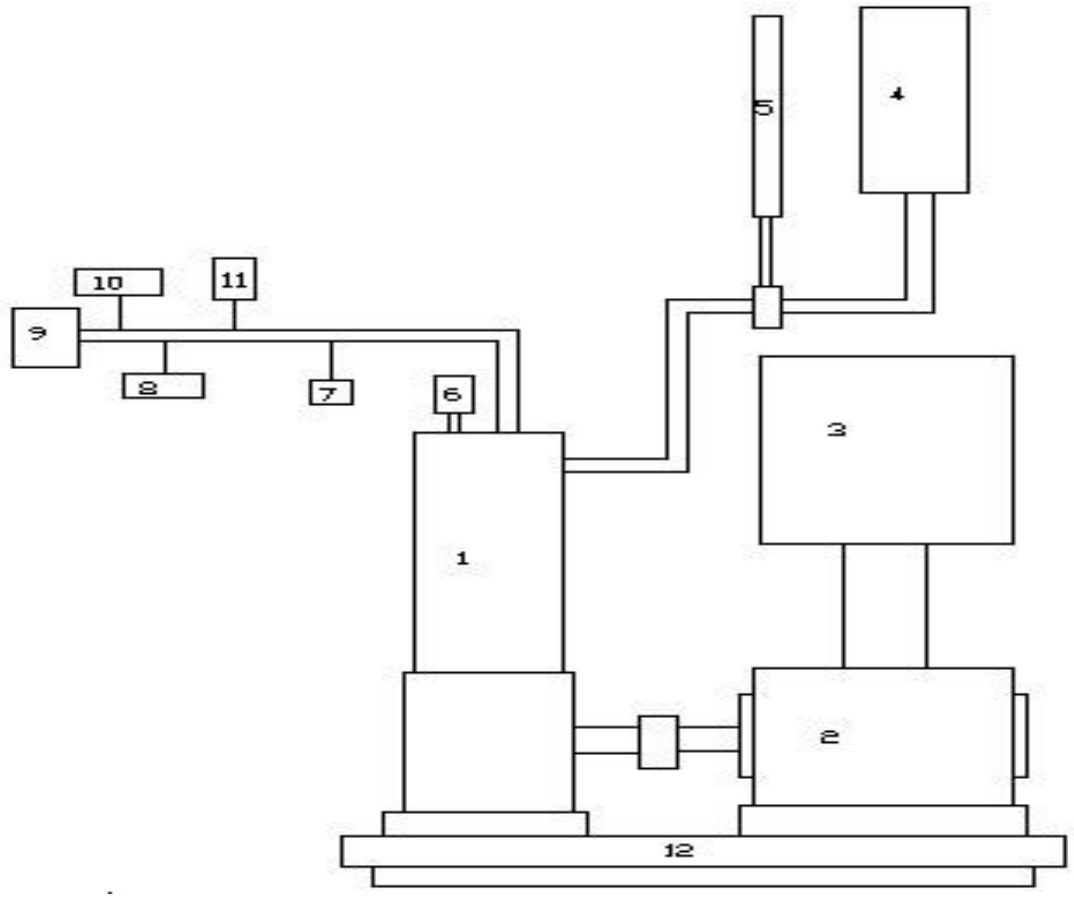

Fig.-1: Schematic of the experimental setup for performance analysis

1. Test Engine

2. Dynamometer

3. Dynamometer panel

4. Fuel Tank

5. Fuel Burette

6. Air Filter

\author{
7.NOx Analyser \\ 8.CO/HC Analyser \\ 9.Muffler \\ 10.Exhaust Gas Temperature Indicator \\ 11.Smoke Meter \\ 12.Engine Test Bed
}

\section{RESULTS AND DISCUSSION}

1. The brake specific fuel consumption of the engine with biodiesel is greater than that of diesel.

2. The exhaust gas temperature of diesel is less than biodiesel at full load conditions. The variation of exhaust gas temperature with brake power is shown in Fig.-2.

3. Brake thermal efficacy of biodiesel is less than diesel.

4. Biodiesel produces significantly less amount of hydrocarbons.

5. Biodiesel produces more smoke emission than that of diesel. The variation of smoke intensity with brake power is shown in Fig.-3.

6. Blending with standard diesel fuel is usually done to improve the engine performance. The ratio of the blend is based on their molecular weight. Blending can also be done with alcohols to increase the 
performance and to reduce emission.

7. The catalytic coating can improve the performance of any engine and combustion rates and this decreases the emission levels. The performance of the engine with catalytic coating using biodiesel as a fuel can be studied in future.

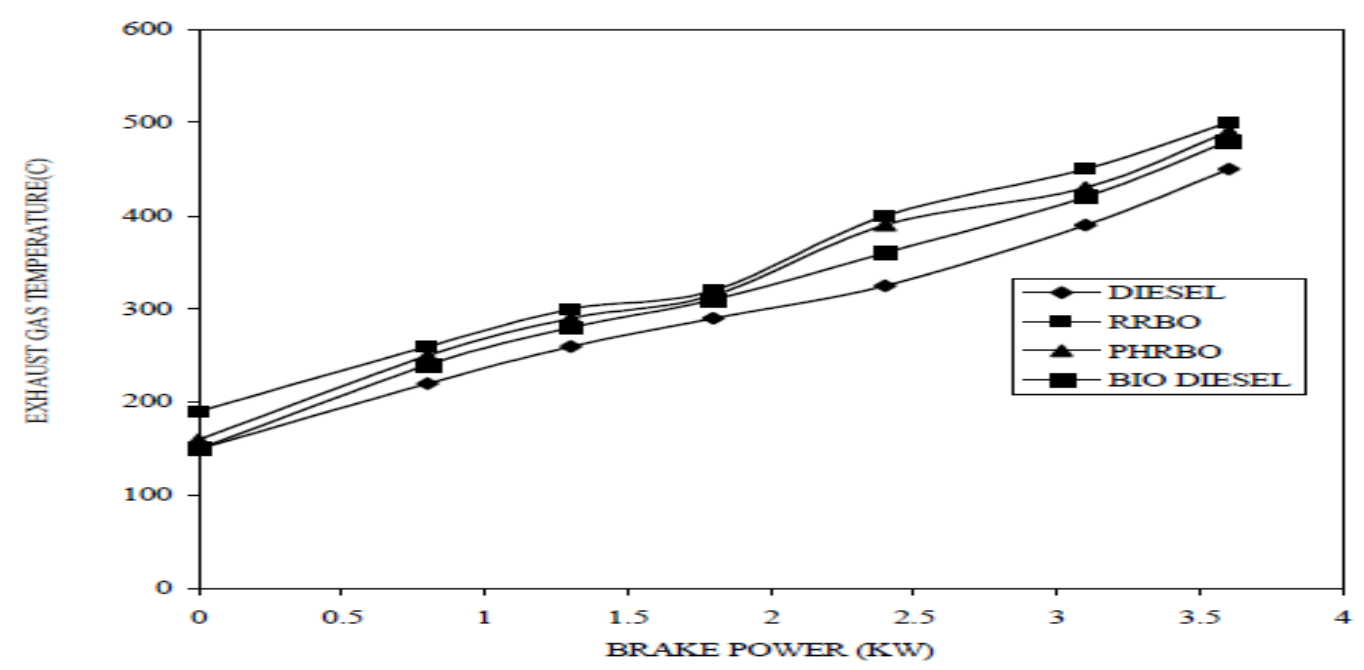

Fig.-2: Variation of exhaust temperature with power

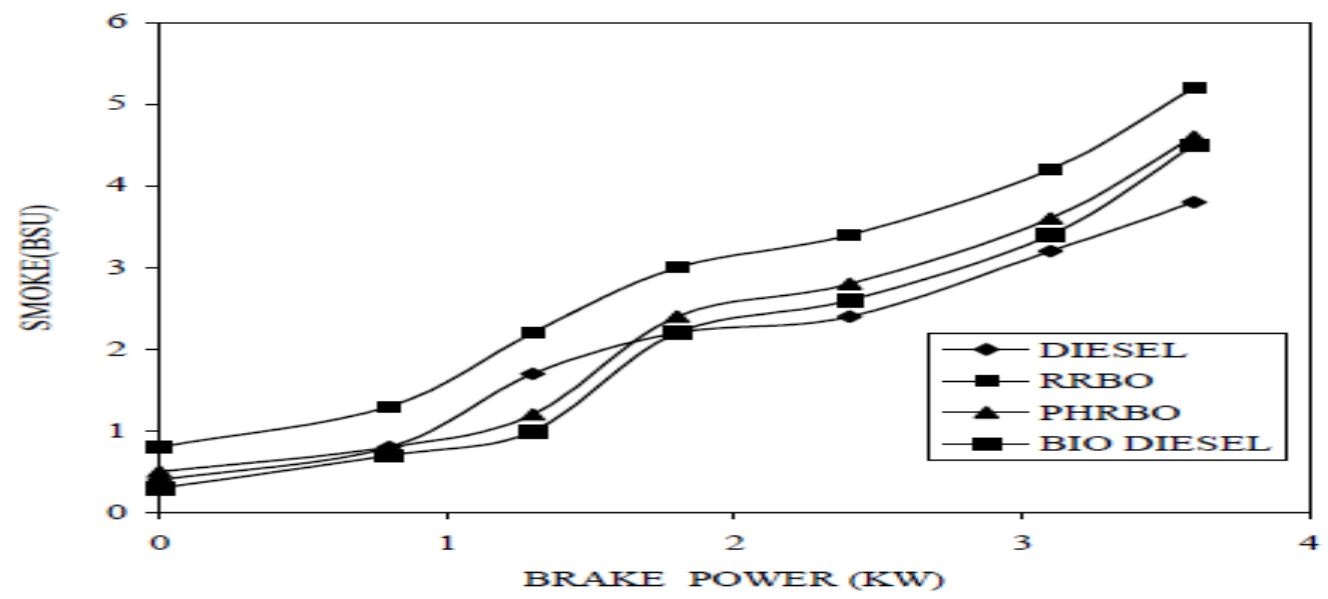

Fig.-3: Variation of smoke level with brake power

8. Micro emulsification is one of the processes of reducing vegetable oils viscosity. The property of the oil obtained by micro emulsified vegetable oil can be studied and its feasibility of using as a fuel in engines can be done in future.

9. Inlet oxygen enrichment can be tried.

10. Combustion characteristics of the vegetable oil can be studied by analyzing P- $\theta$ diagram.

11. Biodiesel produced from other vegetable oils like jatropha, karanji, neem, sunflower, palmoil, carcus, punga can be tried.

\section{REFERENCES}

1. John W. Goodrum and S. Edward Law, ASAE Paper, 897(1982).

2. C.E. Goering, A.W. Schwab, M.J. Daugherty, E.H. Pryde and A.J. Haekin, ASAE Paper, 1472(1982).

3. S. Bhattacharya and C.S. Reddy, ASAE Paper, 157(1994).

4. K. Moshizawa, K. Mori and K.Arai, Proceedings of the Institution of Mechanical Engineers, 2(214), 181(2000). 
RASĀYAN J. Chem.

Vol. 10 | No. 3 |944 - 951 | July - September | 2017

5. A. Seppo Niemi, Petri E. Illikainen, L.K. Makinen and O.K. Laiho, SAE Paper, 970219,21(1997).

6. Kenton R. Kaufman, George L. Pratt, Mariusz Ziejewski and Hans J. Goettler, SAE Paper, 852089, 591(1985).

7. Needhan J.R and D.M. Doyle, SAE Paper, 852101, 651(1985).

8. Dennis L. Siebers, SAE Paper, 852102, 673(1985).

9. Bernard Freedman, Marvin O. Bagby, Timothy J. Callahan and Thomas W. Ryan Iii, SAE Paper, 900343, 153(1990).

10. Walter M. Kreucher, Weijian Han, Dennis Schuetz Zhu ,Zhang Alin, Zhao Ruilan, Sun Baiming and Malcom A. Welss, SAE Paper, 982207, 846(1998).

11. R. Sundara Raman, G. Sankaranarayanan and N. Manoharan, International Journal of Applied Engineering Research, 9(18), 3949(2014).

12. R. Sundara Raman, G. Sankaranarayanan and N. Manoharan, International Journal of Applied Engineering Research, 9(18), 3939(2014).

13. R. Sundara Raman, G. Sankaranarayanan and N. Manoharan, International Journal of Mechanical Engineering and Technology, 6(10), 66(2015).

14. R. Sundara Raman, G. Sankaranarayanan and N. Manoharan, International Journal of Mechanical Engineering and Technology, 6(10), 78(2015).

15. R. Sundara Raman, G. Sankaranarayanan and N. Manoharan, International Journal of Mechanical Engineering and Technology, 6(10), 94(2015).

16. S. Sendilvelan and K. Bhaskar, Rasayan Journal of Chemistry, 9(4), 692(2016).

17. S. Sendilvelan and K. Rajan, Rasayan Journal of Chemistry, 10(1), 190(2017).

18. R. Sundara Raman, G. Sankaranarayanan, N. Manoharan and S. Sendilvelan, Rasayan Journal of Chemistry, 10(2), 434(2017).

19. S. Sendilvelan, K. Bhaskar and S. Nallusamy, Rasayan Journal of Chemistry, 10(2), 450(2017).

[RJC-1664/2017] 